\title{
Funnel plots for comparing institutional performance of antenatal care in pregnant women with diabetes
}

\author{
S Prathapan ${ }^{1}$, D Crowder ${ }^{2}$, R Bell ${ }^{1}$ \\ Ceylon Medical Journal 2011; 56: 164-167
}

\section{Introduction}

Pregnancy complicated with pre-gestational diabetes (PGDM) has a high risk of adverse outcome [1]. In UK, PGDM is the most common medical disorder in pregnancy (0.5\%) [2-3]. Good preparation for pregnancy, including optimising glucose control, improves outcomes [4]. Audits are widely used as tools for quality improvement.

The Northern Diabetes in Pregnancy Survey (NorDIP), is a multi-centre audit in UK and since 1995, it provides yearly feedback by unit, on performance against standards of care for women with PGDM [3]. Comparisons of crude rates indicate wide variation between units. This variation could be due to chance and the current feedback does not indicate statistically significant variation [5].

Funnel plots indicate statistically significant variations outside a control limit [6]. Funnel plots have been used to investigate health outcomes and public health issues [7]. This article presents a study of the use of funnel plots, for visually displaying significant outliers within NorDIP.

\section{Methods}

We used the 2005-2007 data from NorDIP. In each maternity unit a member of the diabetes antenatal healthcare team notifies and records all pregnancy details and seeks consent from the woman. The survey was approved by Newcastle Research Ethics Committee.

\section{Analysis}

Three audit indicators were summarised, relating to key standards of pre-pregnancy care: HbA1c, intake of folic acid and booking at less than 10 weeks gestation. Proportions were calculated from the total number of pregnancies notified at each unit. The funnel plots were plotted using the software developed by the Eastern Public Health Observatory [8]. Funnel plots were created showing units falling outside the 2SD warning limits and 3SD control limits. The information was also visually displayed as colour coded bar charts.

Table 1. Pre-pregnancy care in women with diabetes

\begin{tabular}{crcc}
\hline Unit & HbA1c & Indicators folic acid intake & Booking $<10$ weeks \\
\hline A (n=28) & $18(64 \%)$ & $11(39 \%)$ & $20(71 \%)$ \\
B (n=67) & $18(27 \%)$ & $30(45 \%)$ & $42(63 \%)$ \\
C (n=22) & $10(45 \%)$ & $4(18 \%)$ & $8(36 \%)$ \\
D (n=53) & $40(75 \%)$ & $5(9 \%)$ & $33(62 \%)$ \\
E $(\mathrm{n}=48)$ & $39(81 \%)$ & $24(50 \%)$ & $44(79 \%)$ \\
F (n=23) & $8(35 \%)$ & $9(39 \%)$ & $19(70 \%)$ \\
G(n=61) & $35(57 \%)$ & $30(49 \%)$ & $42(69 \%)$ \\
H(n=43) & $23(53 \%)$ & $14(33 \%)$ & $36(77 \%)$ \\
I (n=25) & $18(72 \%)$ & $15(60 \%)$ & $20(74 \%)$ \\
J (n=29) & $27(93 \%)$ & $21(72 \%)$ & $24(80 \%)$ \\
K (n=45) & $33(73 \%)$ & $17(38 \%)$ & $29(64 \%)$ \\
All units & $44.8(61 \%)$ & $16.4(41 \%)$ & $28.8(68 \%)$ \\
\hline
\end{tabular}

${ }^{1}$ Institute of Health and Society Newcastle University, Newcastle upon Tyne, NE2 $4 A X$, ${ }^{2}$ Regional Maternity Survey Office, Newcastle, NE2 4AA.

Correspondence: SP, e-mail: <drpbshamini@yahoo.com>. Received 21 January and revised version accepted 1 June 2011. Competing interests: none declared. 


\section{Results}

There were 444 pregnancies reported to NorDIP between 2005 and 2007. The number delivered in each unit ranged from 22 to 67 women (Table 1 ). A wide variation was noted in these crude rates for each indicator between the units. The biggest range (27\% to 93\%) among the indicators was for pre-pregnancy HbA1c recording.
The variability among the units for all three indicators is shown in Figure 1. Figure 2 shows the same data in colour coded bar charts. For 'pre-pregnancy HbA1c' and 'folic acid taken pre-pregnancy', one unit was above the upper 3 standard deviation (indicating favourable performance) and another unit below the 3SD (Figure 1a,1b).

Figure 1. Funnel plots for unit comparisons.

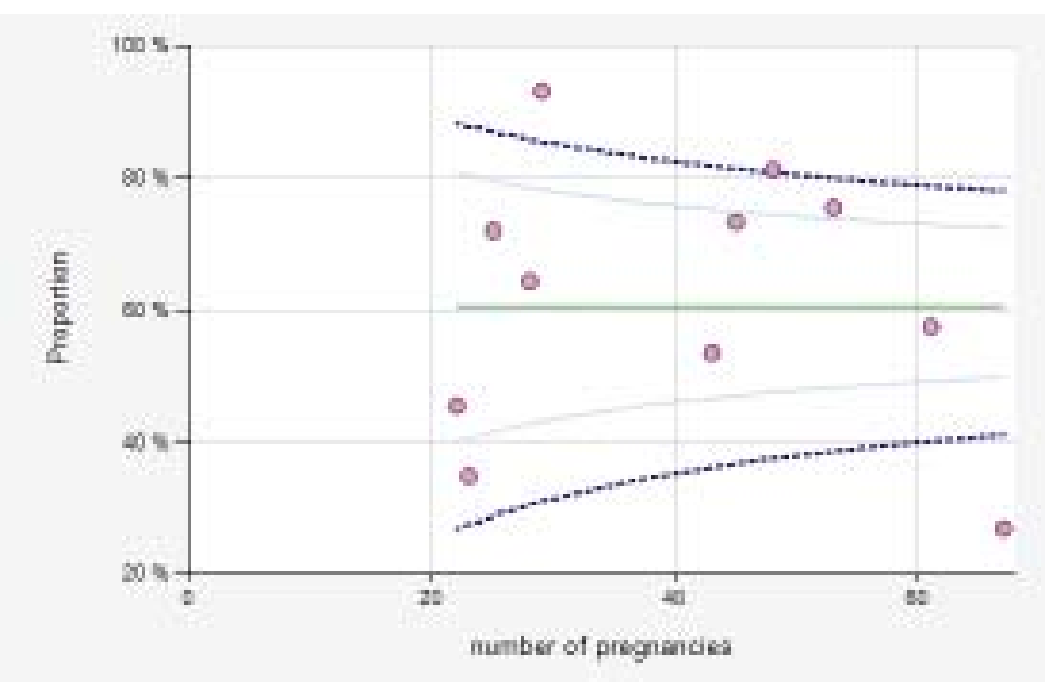

Figure 1a. HbA1c recorded pre-pregnancy.

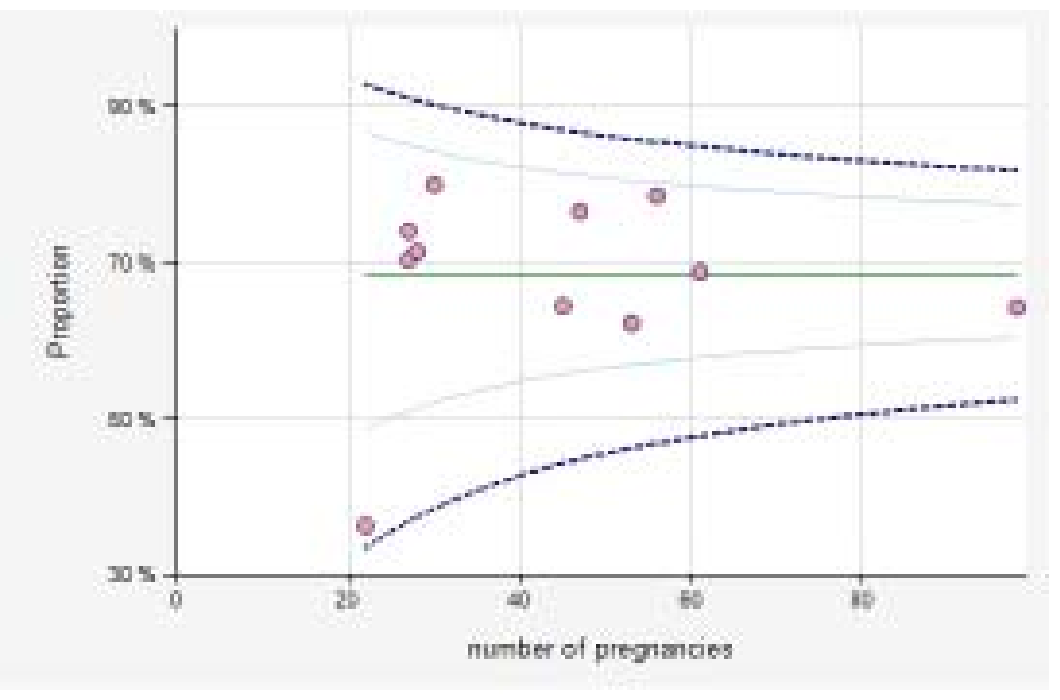

Figure 1b. Folic acid taken pre-pregnancy. 


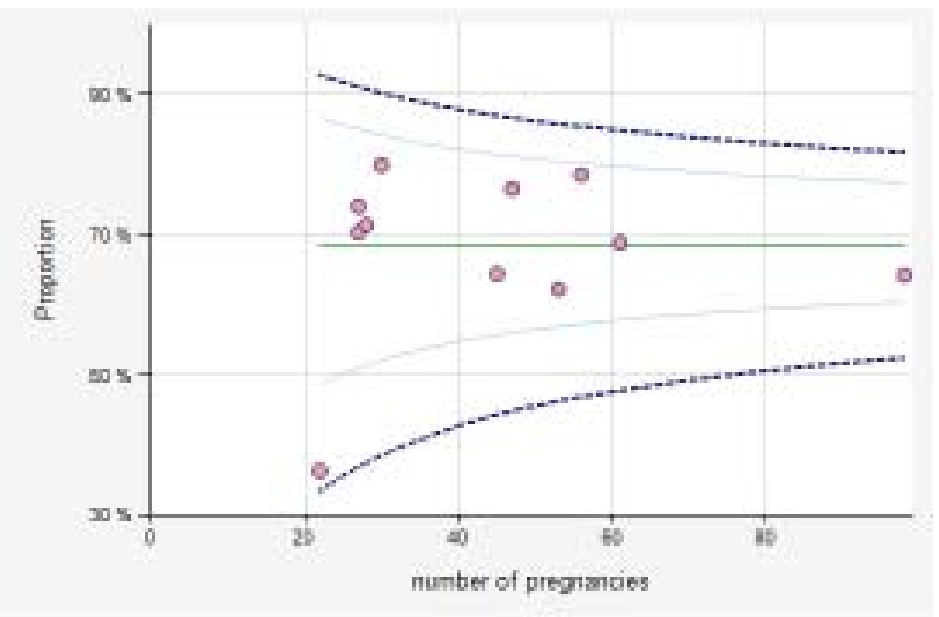

Figure 1c. Booking at $<10$ weeks.

Figure 2. Bar charts showing units with limits by unit, 2005-2007.

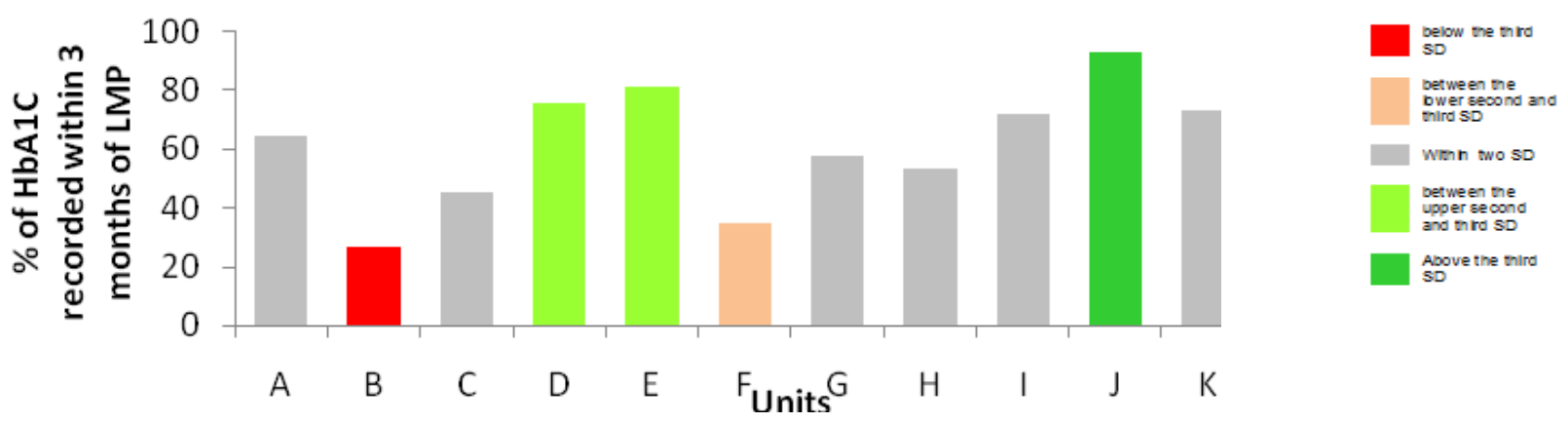

Figure 2a. HbA1c recorded within 3 months of LMP (\% of all pregnancies).

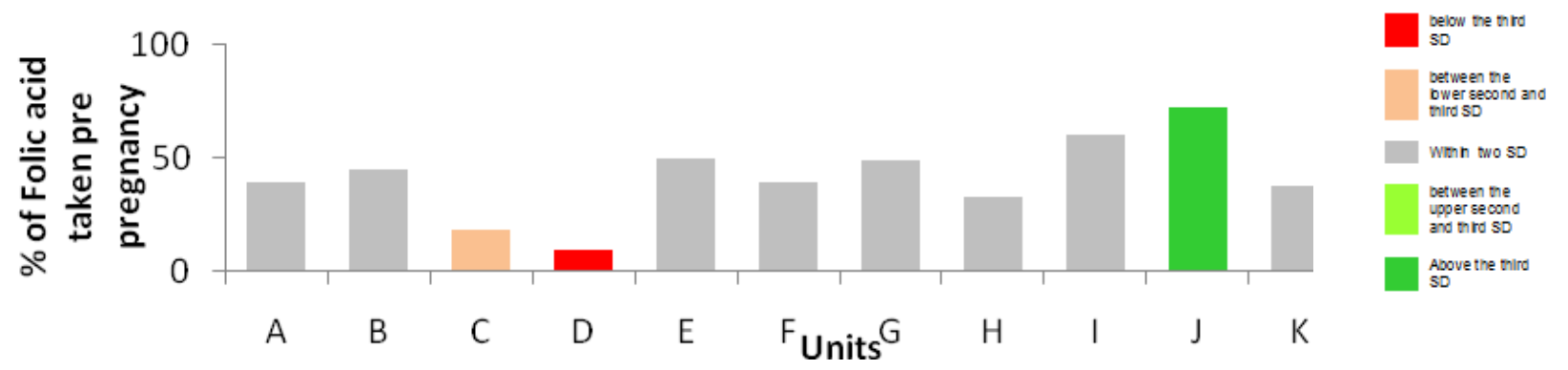

Figure $2 b$. Folic acid taken pre-pregnancy, by unit (\% of all pregnancies).

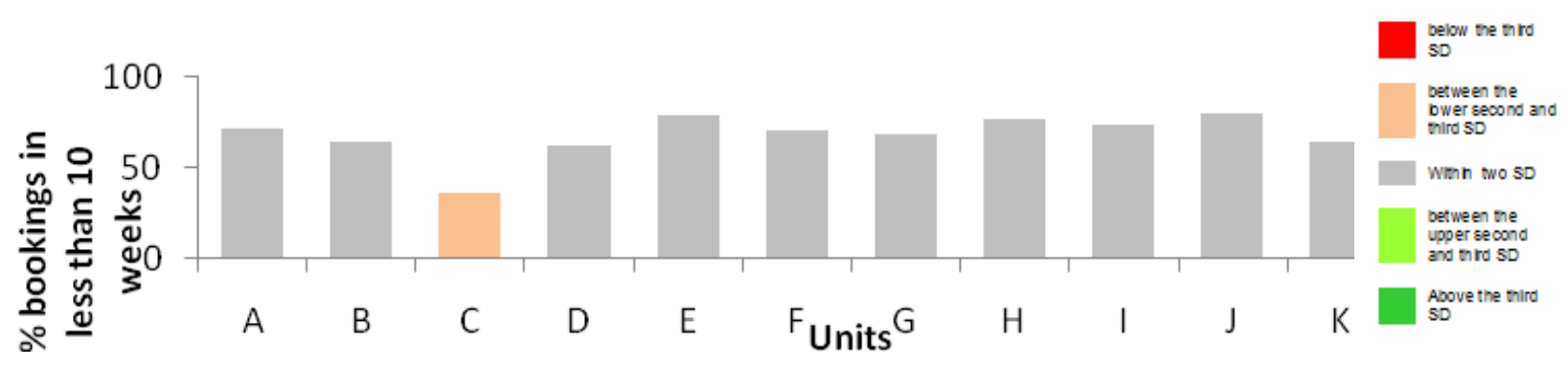

Figure 2c. Bookings made at less than 10 weeks (\% of all pregnancies). 
For bookings at less than 10 weeks, all the units other than unit $\mathrm{C}$ were within the $2 \mathrm{SD}$, which shows that the variability between units was within control limits, and consistent with chance variation (Figure 1c, 2c). Unit D, colour coded as red and falling below the 3SD on the indicator 'folic acid taken pre-pregnancy' was significantly different from all the other ten units (Figure 2b). The units that were colour coded grey showed a wide range of variability, but within the 2SD limits (Figure 2).

\section{Discussion}

This article describes two practical methods of presenting data which allow rapid visual identification of statistical outliers. This helps to distinguish normal chance variability from significant variation which requires investigation. These methods are economical, not labour intensive and allow for statistically reliable data to be fed back to the units in the region.

Funnel plots and the alternative methods based on it, appear an attractive method of presenting data to decision-makers in maternity units and local health authorities. These methods identify outlying positions more clearly than tables or simple bar charts and help prompt an organisation to reflect on their position. The underlying reasons for variability require further investigation and underline the need for action to improve standards.

\section{References}

1. Lawrence JM, Contreras R, Chen W, Sacks DA. Trends in the prevalence of pre-existing diabetes and gestational diabetes mellitus among a racially/ethnically diverse population of pregnant women, 1999-2005. Diabetes Care 2008; 31: 899-904.

2. National Institute for Health and Clinical Excellence. Diabetes in pregnancy: management of diabetes and its complications from preconception to the postnatal period. In: Health, editor. RCOG Press; 2008.

3. Northern Diabetes in Pregnancy Survey (NorDIP): Regional and unit-based audit analysis 2005-2007. NEPHO occasional paper no 38; 2010: NEPHO, Stockton-on-Tees. Available at: http://www.nepho.org.uk/publications. php5?rid=806\&hl=diabetes.

4. Hawthorne SG, Robson S, Ryall EA, Sen D, Roberts SH, Platt MPW. Prospective population based survey of outcome of pregnancy in diabetic women: results of the Northern Diabetic Pregnancy Audit, 1994. British Medical Journal 1997; 315: 279.

5. Guthrie B, Love T, Fahey T, Morris A, Sullivan F. Control, compare and communicate: designing control charts to summarise efficiently data from multiple quality indicators. Quality and Safety in Health Care 2005; 14: 450-4.

6. Young RJ, Holmes EM, Casson IF, Maresh M. The North West Diabetic Pregnancy Audit: a practical system for multicentre diabetic pregnancy audit. Diabetic Medicine 2008; 25: 496-500.

7. Mohammed MA, Cheng KK, Rouse A, Marshall T. Bristol, Shipman, and clinical governance: Shewhart's forgotten lessons. Lancet 2001; 357: 463-7.

8. Spiegelhalter DJ. Funnel plots for comparing institutional performance. Statistics and Medicine 2005; 24: 1185-202. 